\title{
Continuous outreach activities performed by a student project team of undergraduates and their program topics in optics and photonics
}

\section{Makoto Hasegawa, Seika Tokumitsu}

Makoto Hasegawa, Seika Tokumitsu, "Continuous outreach activities performed by a student project team of undergraduates and their program topics in optics and photonics," Proc. SPIE 9946, Optics Education and Outreach IV, 99460D (27 September 2016); doi: 10.1117/12.2235311

SPIE Event: SPIE Optical Engineering + Applications, 2016, San Diego, California, United States 


\title{
Continuous outreach activities performed by a student project team of undergraduates and their program topics in optics and photonics
}

\author{
*Makoto Hasegawa, Seika Tokumitsu \\ Chitose Institute of Science and Technology \\ 758-65 Bibi, Chitose, Hokkaido, 066-8655 Japan
}

\begin{abstract}
The out-of-curriculum project team "Rika-Kobo", organized by undergraduate students, has been actively engaged in a variety of continuous outreach activities in the fields of science and technology including optics and photonics. The targets of their activities cover wide ranges of generations from kids to parents and elderly people, with aiming to promote their interests in various fields of science and technologies. This is an out-of-curriculum project team with about 30 to 40 undergraduate students in several grades and majors. The total number of their activities per year tends to reach 80 to 90 in recent years. Typical activities to be performed by the project team include science classes in elementary and/or secondary schools, science classes at other educational facilities such as science museums, and experiment demonstrations at science events. Popular topics cover wide ranges from explanations and demonstrations of nature phenomena, such as rainbow colors, blue sky, sunset color, to demonstration experiments related to engineering applications, such as polarization of light, LEDs, and optical communications. Experimental topics in optics and photonics are especially popular to the audiences. Those activities are very effective to enhance interests of the audiences in learning related knowledges, irrespective of their generations. Those activities are also helpful for the student members to achieve and/or renew scientific knowledges. In addition, each of the activities provides the student members with effective and advantageous Project-Based-Learning (PBL) style experiences including manufacturing experiences, which are advantageous to cultivate their engineering skills.
\end{abstract}

Keywords: outreach, PBL, out-of-curriculum, science education, career development, engineering education

\section{INTRODUCTION}

Outreach activities by scientists, researchers and engineers are very important for enhancing understandings of people towards various fields of science and technology. Those activities are useful for people, who are not deeply involved in science and technology in their daily life, to know latest research results and achievements in various fields of science and technology. The activities are also effective and important for those people to obtain certain knowledges on several important topics, e.g., climate changes and global warming, so that they can think of and have their own opinion on such topics.

Outreach activities targeting children and students are especially important for the purpose of encouraging them to get interested in studying wide or at least certain fields of STEM (science, technology, engineering and mathematics) education.

For example, in Japan, concerns have been emerged for recent years about lack of interests of students in secondary school generations towards science. Specifically, although children in elementary schools are likely to be interested in science, several surveys often show that percentages of students who still like studying science (especially physics) in junior high schools and high schools are likely to reduce. One of often-spoken explanations for such phenomena is that they do not have enough experiences of science experiments at secondary schools. In science classes (such as physics) at schools, instead of spending time in experiments, students will learn knowledges in related fields of science from lectures based on textbooks. This style of learning may be effective for them to obtain sufficient levels of knowledges to pass entrance examinations for next levels of education (in other words, universities or colleges for high school students). However, if students are not so enthusiastic in studying science, such a style of learning will be boring and they will lose their interests in studying science.

*hasegawa@photon.chitose.ac.jp ; phone/fax +81-123-27-6059.

Optics Education and Outreach IV, edited by G. Groot Gregory, Proc. of SPIE Vol. 9946, 99460D

(C) 2016 SPIE $\cdot$ CCC code: $0277-786 X / 16 / \$ 18 \cdot$ doi: $10.1117 / 12.2235311$ 
As one of countermeasures in such situations, various science events within and out of schools have been organized in which children and students, especially in elementary school ages, can have chances to experience various science experiments. Organizers are hoping that once children and students become interested in science and technology through experiment experiences at those events, they will then voluntarily keep studying related fields even if class style at schools may not be changed.

The student project team "Rika-Kobo", organized by undergraduate students, has been actively engaged in various activities, mainly targeting kids, parents and ordinary people in local community and aiming to promote their interests in the fields of science and technologies ${ }^{1-4}$. This is an out-of-curriculum project team with about 30-40 student members in several grades with different majors. The total number of their activities per year tends to reach 70-80 in recent each year, which include science experimental classes in elementary and/or secondary schools, science experimental classes at other educational facilities, and science experiment events. The activities are warmly welcomed in the local community and their good reputation leads to the fact that the total number of their activities finally exceeded 90 for the Japanese fiscal year 2015. Experimental topics in optics and photonics are especially popular to the audiences. Those activities are very effective to enhance interests of the audiences in learning related knowledges, irrespective of their generations.

Those activities are also helpful for the student members to achieve and/or renew scientific knowledges. In addition, each of the activities provides the student members with effective and advantageous Project-Based-Learning (PBL) style experiences including manufacturing experiences, which are advantageous to cultivate their engineering skills.

\section{CURRENT ACTIVITIES OF THE STUDENT PROJECT TEAM ${ }^{1-4}$}

\subsection{Outline of the project team}

The student project team was officially organized over ten years ago. One of the authors was involved in establishment of the project team, and has been served as their supervisor since then. The project team has been operated in the out-ofcurriculum basis, in other words, the activities of the project team are not included in the official education curriculum. Therefore, the student members will not obtain any credit through participation into the activities or their GPA scores are not changed based on their performances in the activities. Any students who get interested in the activities can voluntarily become members of the team anytime, irrespective of their major nor grade. In a typical situation, new members will come and join the project team when they enter the university as fresh persons, but sometimes student(s) in second or higher grades may join the team. Most of the student members are likely to continue their activities until their graduation, and sometimes, even as a graduate student. As a result, the project team is likely to have around 30 to 40 student members from fresh persons to seniors. Thus, inter-grade collaboration among the student members is possible in the team. Their majors also vary from electrical engineering to chemistry and material science.

In spite of the fact that the activities of the project team are out-of-curriculum basis and are not included in the official educational curriculum, university administration provides the project team with annual financial support so as to cover expenses. This is because the activities of the project team now play a certain important role as outreach activities and regional collaborations of the university itself.

In addition, one laboratory room is available dedicated to their daily activities. In this laboratory room, various equipment and apparatuses, tools and kits to be used in their activities are stocked, as can be seen in Fig.1(a).

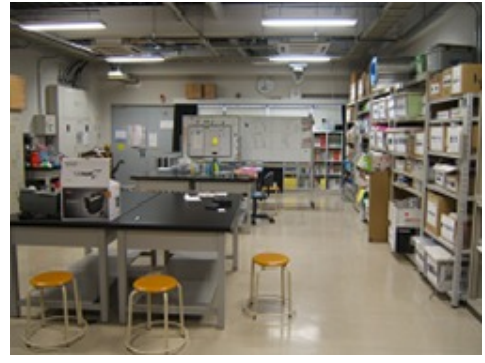

(a) The inside of the project lab room

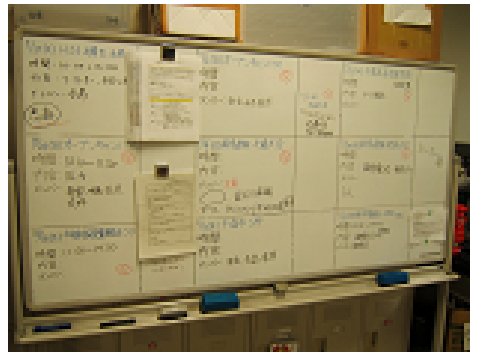

(b) A white board with activity schedule ${ }^{2}$

Figure 1 . Photos of the laboratory room dedicated to the dairy activities of the project team. 
The student members can come to this lab room anytime, for example, between and/or after their classes so as to do their necessary work. The activities of the team are mainly self-disciplined by the student members themselves, and detailed advices/instructions from the author as the supervisor or other teachers are usually unnecessary.

More specifically, although the activities of the project team are out-of-curriculum basis, most of them have certain "outof-campus clients" (such as school teachers, parents, staffs of education facilities or other organizations), and are actually performed under the name of the university based on requests from those clients. Therefore, the student members of the project team are strongly required to have sufficient levels of responsibility for organizing and performing successful tasks. At the same time, even in such situations, daily activities of the project team are basically self-controlled and selfdisciplined by the student members. For example, they should be responsible for schedule management and other organizing tasks by themselves. As a result, certain ideas have emerged for the purpose of realizing successful tasks, for example, they are likely to use white boards in the lab room for schedule and task management, as shown in Fig.1(b).

In such circumstances, the student members are required to work as a team in collaboration. The members in the upper grades lead the lower grade members. Through those experiences over a few years (such as from the first grade to the upper grades), the student members can have opportunities to improve their various skills to be required in actual working environments, such as collaboration, leadership, schedule management.

\subsection{Examples of the activities}

The activities to be performed by the student project team include various styles, and can be categorized, for example, as follows.

(1) Science experimental classes in local elementary and junior high schools:

The team has opportunities for performing science experimental classes at some local schools for the purpose of stimulate interests of students to various fields of sciences and technologies. More specifically, for two elementary schools, the project team performs a series of several science experimental classes for the 5th grade and 6th grade children for over 10 years. In addition, the team also performs classes once a year for the 7 th grade students at one of junior-high schools in the local community.

In those science experimental classes, one student member serves as a teacher for giving general explanations to the whole class, while several other members act as instructors for respective small groups of children so as to provide them with specific explanations and guidance on experimental procedures in detail, as can be seen in Fig.2. The topics of those experimental classes are often not directly related to the subject-matters to be taught in science classes of elementary schools and junior high schools, and include, for example, spectrum of light, sunset colors, optical communication, and air pressure. In some cases, however, the project team prepares some classes in view of the subject matters in science classes in elementary schools, such as uses of electricity, for the purpose of assisting teachers in elementary schools in preparation of experiments. In the junior high school classes, the project team is likely to ask junior high school students to do various measurements and then encourage them to make discussions based on the measured results.

Before each of such science classes, the student members often have to prepare for necessary experimental equipment or kits, and some of them are of original hand-made version.
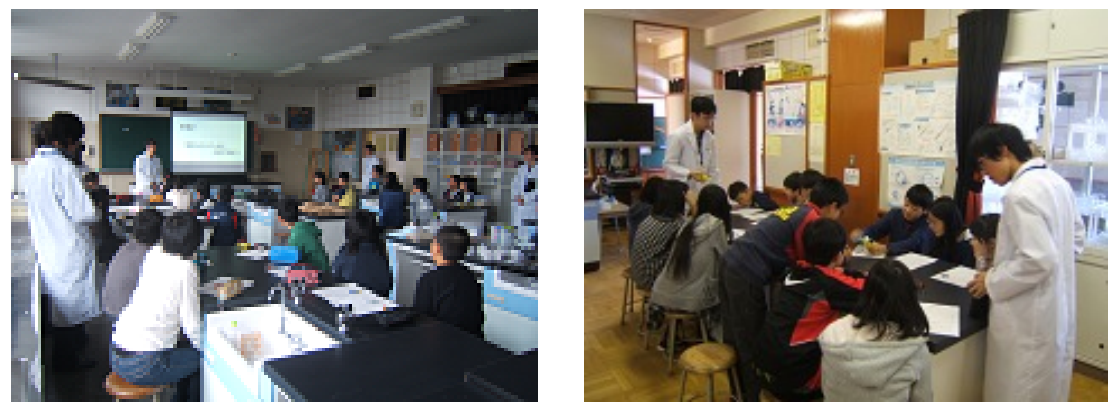

Figure 2. Photos of the science experimental classes at an elementary school ${ }^{2-3}$. 
(2) Science experimental classes at other local educational facilities:

Similar science classes are also performed at other educational facilities in the local community, such as a local science museum and children's houses, see photos in Fig.3. In such situations, children' ages and degrees of their interests are likely to widely vary. In addition, mental atmospheres of children are often quite different from those in school classrooms, specifically, children are likely to get much relaxed. Thus, even when the same or similar topics as in schools are to be performed, certain adjustment or revisions are often necessary.

From the year 2015, science classes at some kindergartens have also started.
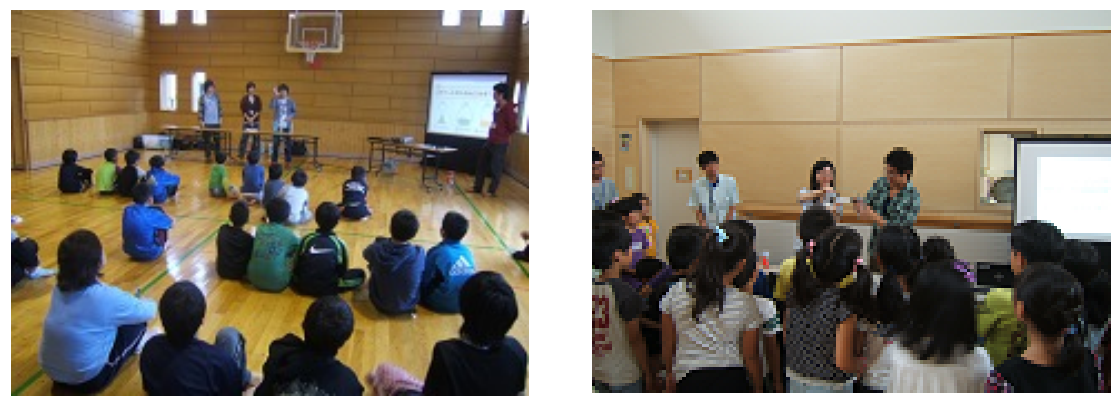

Figure 3. Photos of the science experimental classes at a children' house in the local community ${ }^{1-2}$.

(3) Science demonstration activities and science experimental classes at various events and other opportunities:

The project team is often invited by various kinds of local organizations to participate in various events both indoors and outdoors and/or to perform science demonstrations, science experimental classes or other styles of activities under different situations, as shown in photos in Fig.4.

The project team is also sometimes asked to perform science classes targeting for elderly generations as one of life-long education programs in the local community.
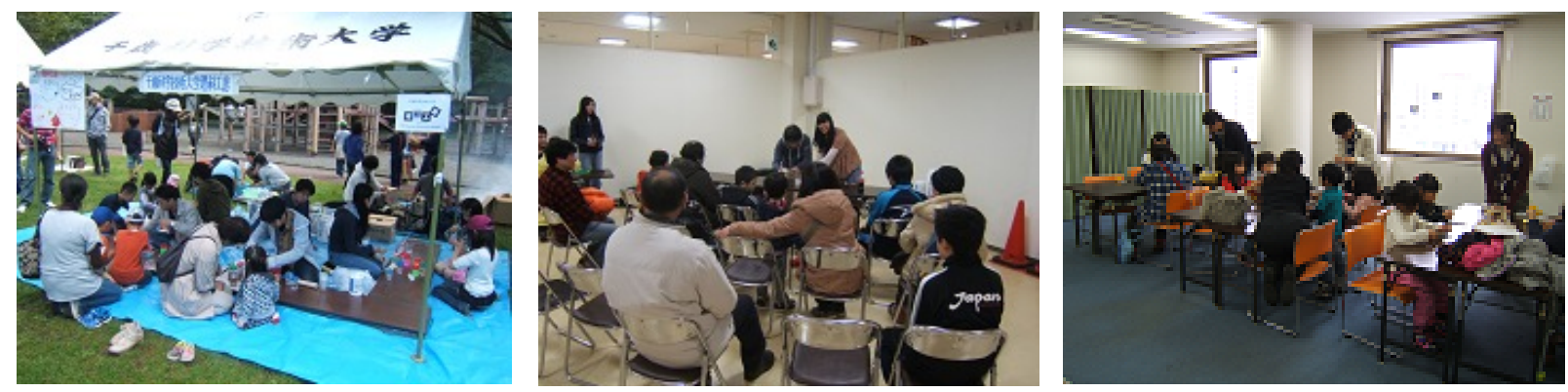

Figure 4. Photos of various activities of the project team in the local community ${ }^{1-2}$.

\subsection{The number of activities performed by the student project team each year}

Fig. 5 shows the total number of the activities performed by the student project team for each Japanese fiscal year (from the beginning of April to the end of the next year March) ${ }^{3}$. The number per year reached at around 60-70 since 2010, and further exceeded 80 in the recent years. Each of these activities, as briefly introduced in the above, is often based upon requests from various out-of-campus clients in the local community (both organizations and individuals), such as elementary and secondary schools, Parent and Teacher Association of local schools, science museums and other social educational facilities, and so on. Significant increases in the number of the activities performed by the student project team over years imply that those activities are surely earning certain good reputations and being warmly welcomed in the local community. 


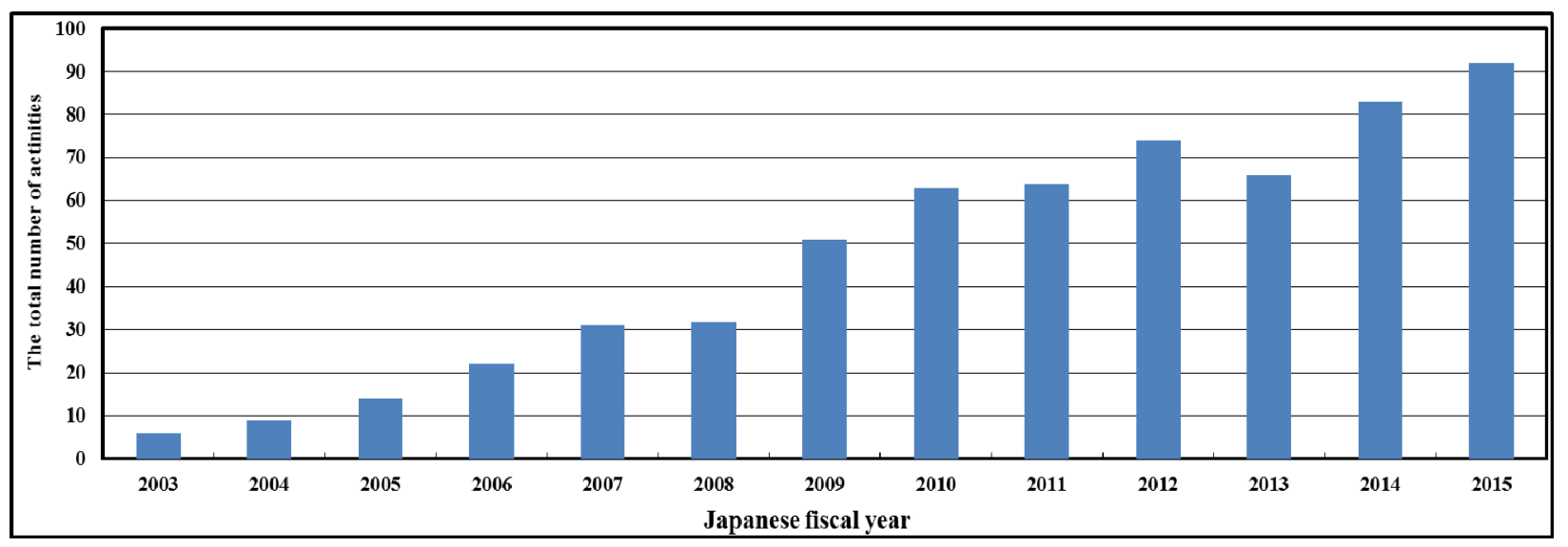

Figure 5. The total number of the activities performed by the student project team for each Japanese fiscal year ${ }^{3}$.

\section{SOME EXEMPLARY TOPICS OF THE ACTIVITIES IN THE FIELDS RELATED TO OPTICS AND PHOTONICS}

In the various activities to be performed by the student project team, topics in the fields related to optics and photonics are very popular to children. In some cases, those are very effective to attract interests of children and students who attend experimental classes or experiment demonstration event.

\subsection{Some topics for science experimental classes in elementary schools}

Typical topics to be performed for experimental classes for 5th grade classes and 6th grade classes of the two elementary schools each year will be as follows:

- $\quad$ For 5th grade classes:

$>$ Fundamental properties of light (reflection and refraction, spectrum of white light)

$>$ Optical communication

- $\quad$ For 6th grade classes in summer:

$>$ Sunset color and blue sky

$>$ Air and water pressure

- $\quad$ For 6th grade classes in winter:

$>$ Electric power generation and their storage in capacitors

$>$ Static electricity

In the class for "Fundamental properties of light", children in the class are to learn how light beams will propagate and behave (such as reflection and refraction) and also how white light will be divided into several different colors through basic experiments with, for example, a prism.

In such a case, a glass prism will be desirable but usually expensive, resulting in simple demonstration in the classroom. Although demonstration with a glass prism is performed, the project team usually prepare sufficient numbers of gelatin prisms (see Fig.6) ${ }^{4}$, so that each of children in one class (usually, around 25 to 35 children) can use one prism and actually observe when light beams will reflect and/or refract in the prism. Those gelatin prisms are very useful because they can be prepared at a low cost, and can be easily handled. Each of children in the class can observe behaviors of light beams by themselves with their own gelatin prisms. 

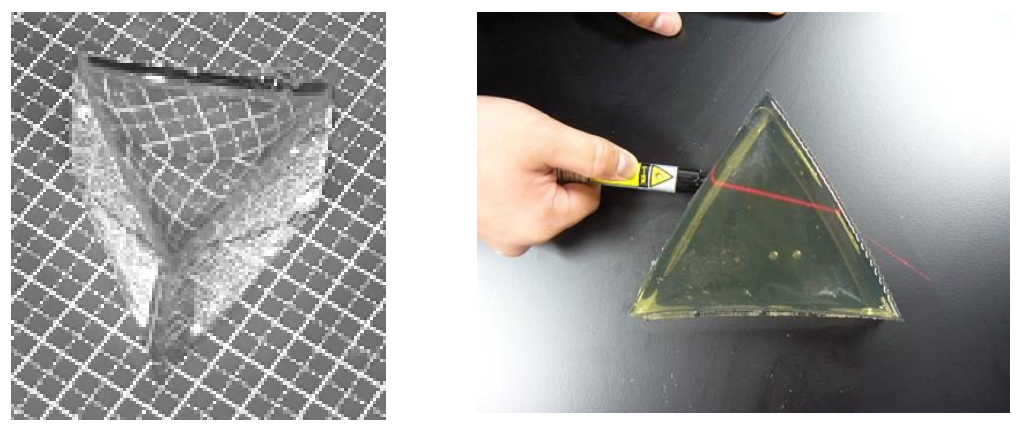

Figure 6. A prism made of gelatin ${ }^{4}$.

(In actual experimental classes for elementary school students, a laser pointer is NOT used for safety reasons.)

In the class for "sunset color and blue sky", a hand-made 50 cm-long water tank is provided for each group of 4 to 6 children, and suspension liquid is prepared from acryl-emulsion and tap-water in the tank. A conventional electric torch or a white-LED torch is placed at one end of the water tank as a light source, so that children can observe changes in colors of light beams travelling from the light source through the suspension liquid in the water tank. When viewed from the opposite end of the water tank, the so-called "sunset color" can be observed as shown in Fig.7(a). In addition, children can also recognize that different colors are visible in accordance with distances from the light source (the electric torch), as shown in Fig.7(b), when viewed from the side of the tank. After such observations, reasons of appearing sunset color as well as blue sky are explained. Moreover, when the white-LED torch is employed as the light source, observed colors are slightly different from those observed with the conventional electric torch, see Fig.7(c). Some of children may be aware of such differences during the class 5 .

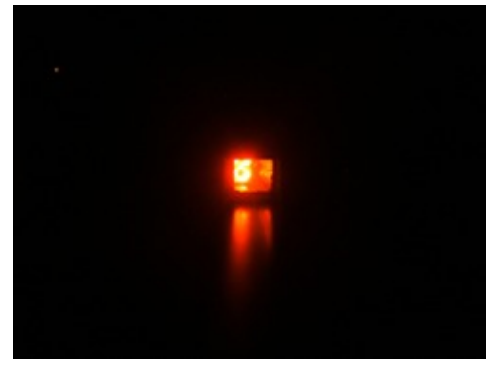

(a) when viewed from the end

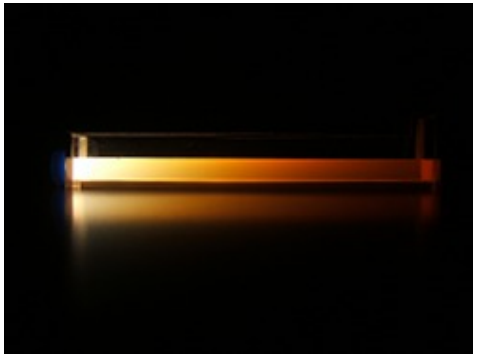

(b) when viewed from the side

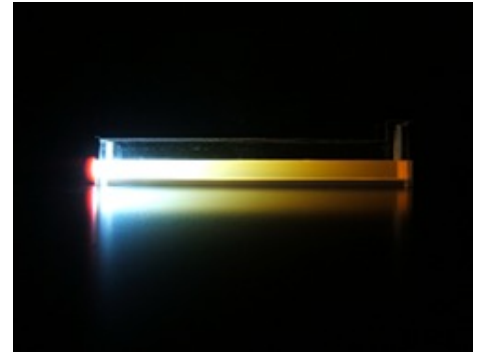

(c) side view with white-LED torch

Figure 7. Typical observed colors with hand-made water tanks in the experiment on sunset color and blue sky ${ }^{5}$.

\subsection{Some topics for science experimental classes with secondary school students}

For experimental classes with students of secondary schools, contents of slightly advanced levels will be often selected. One of such advanced class topics is calculation of wavelength of light beams.

Typically, students in the class are first encouraged to observe spectrum of light beams by allowing light beams emitted from a conventional electric torch to pass through diffraction gratings onto a screen. And then, the conventional electric torch is replaced with a He-Ne laser and the students are ask to observe how laser beams will behave after passing through the same diffraction gratings. Then, they are encouraged to make measurements and calculations to obtain the wavelength value of the He-Ne laser. If extra time is available, the conventional electric torch is again employed as the light source, and measurements and calculations of wavelengths for light beams with different colors can be done, so that the students can actually realize which of red and blue color light will have shorter or longer wavelength through their own experiences of measurements. 


\subsection{Some topics in engineering fields}

As an example of demonstration topics in engineering fields related to photonics, a simplified demonstration set for optical communication is often used in various situations.

This optical communication demonstration set, shown in Fig.8, has a very unique aspect in which LEDs can be utilized, not only as light emitting components or light sources, but also as light receiving components ${ }^{6-8}$. By employing this aspect, effective science experiment demonstration on optical communication can be performed (see Fig.9). For children and students with lower grade (i.e., in their younger ages) as well as people who are not familiar with optical communication, simple demonstration of music transmission via light beams emitted from an LED can attract their interests. For high school or university students and other people who have some or certain knowledges on LEDs and know their function as light emitting components, unexpected effects of light receiving performances of LEDs can be effective to let them get interested and encourage them to obtain further knowledges and explanations on the functions.

Moreover, appropriate selections of LEDs with different colors as the light transmitting and receiving components selectively realize successful transmission and reproduction of audio signals (music). Such demonstration can act as a useful introductory tool for explaining relationships among colors of light (wavelengths or frequencies) from LEDs, their energy levels and band gap energies of semiconductor materials used in the LEDs.

As an advanced version, a simplified demonstration set for wavelength multiplied optical communication can also be prepared with a white-color LED, as shown in Fig. $10^{9}$. More specifically, in this demonstration set, a white-color LED including a red-color LED element, a green-color LED element and a blue-color LED element is employed as a light source. Operating current levels for these LED elements can be independently modified in accordance with different audio signals. When receiving the modulated light, three different audio signals are simultaneously demodulated. By employing appropriate filters, one among these three audio signals can be selected to be reproduced.

This demonstration set is also effective and useful for explaining primary colors of light.

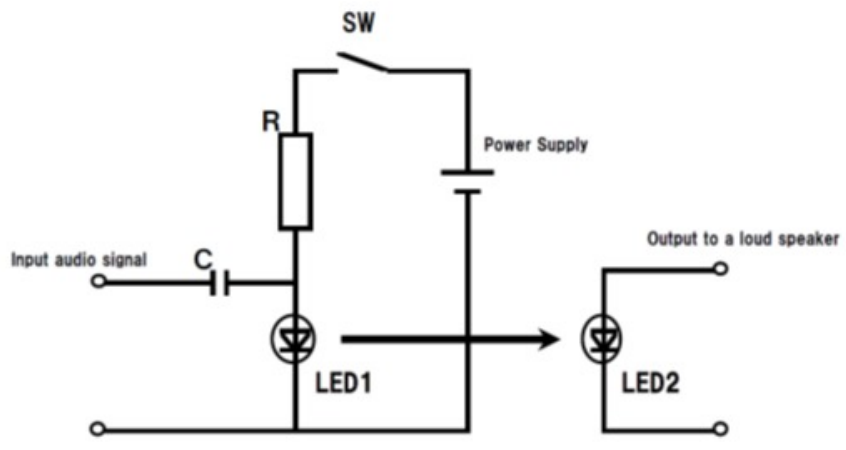

(a) Basic circuit diagram ${ }^{7-8}$

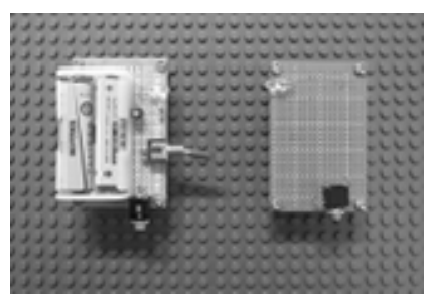

(b) Light transmitting (left) and receiving (right) circuits $^{8}$

Figure 8. Circuit diagram and actual circuits of the experimental set for optical communication ${ }^{7-8}$.

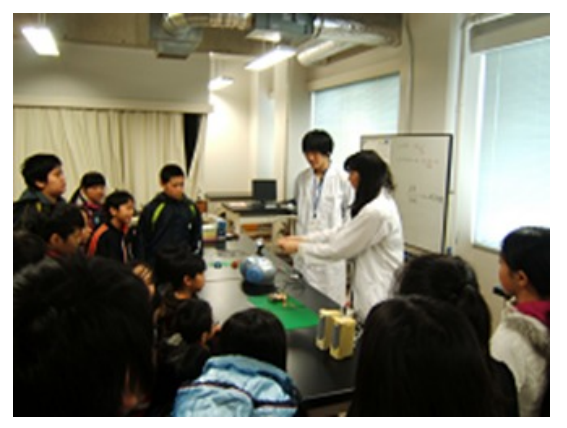

(a) Explanation in the science class for elementary school students

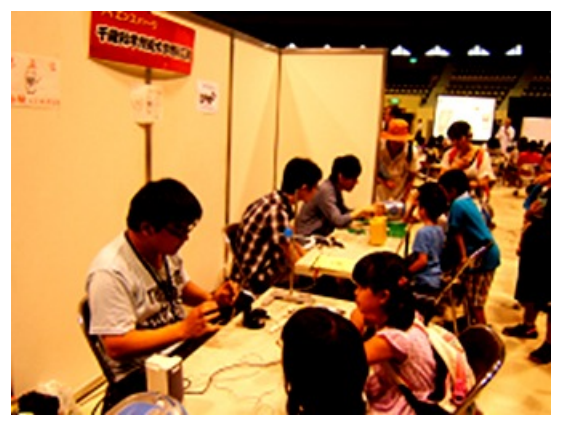

(b) Demonstration at the science event

Figure 9. Explanation and demonstration for optical communication ${ }^{7}$. 


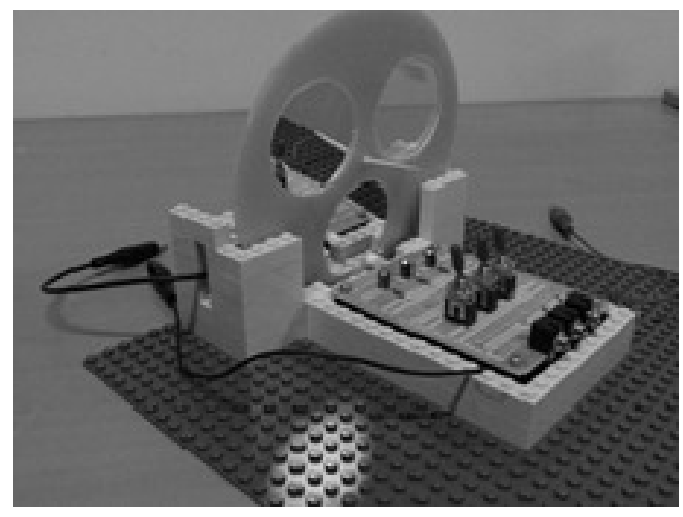

Figure 10. A simplified demonstration set for wavelength multiplied optical communication with a white-color LED 9 .

\subsection{Some topics for science experiment demonstrations}

Several other topics which can dramatically attract peoples' attentions (children, students, parents, and others in all generations) in a short period of time may be suitable especially for science demonstration events. This is because people may not pay attention to nor have interests in demonstrations, and thus giving quick surprise to them may be especially effective to keep their attentions and interests.

One of such topics is related to polarization phenomena of light. Typical demonstration topic is coloring demonstration in which a piece of sheet or object made of certain plastic materials is placed between a pair of polarizing sheets so as to show various coloring effects caused by birefringence and retardation phenomena within the plastic materials placed between the pair of polarizing sheets.

Another example relating to polarization, which can be effective for attracting viewers' attentions, can be referred to as "a black wall" or "a black plate", as shown in Fig.11. By placing several polarizing sheets in a specific directional relationship, a phantom black wall or plate can be observed. A large scale version in which people can actually walk through the phantom black wall has been prepared by the project team recently and actually demonstrated at several events. After having fun with those demonstration materials, explanations of the principle about polarization phenomena as well as a reason why such a phantom black wall or plate can be observed will be offered when viewers show interests.
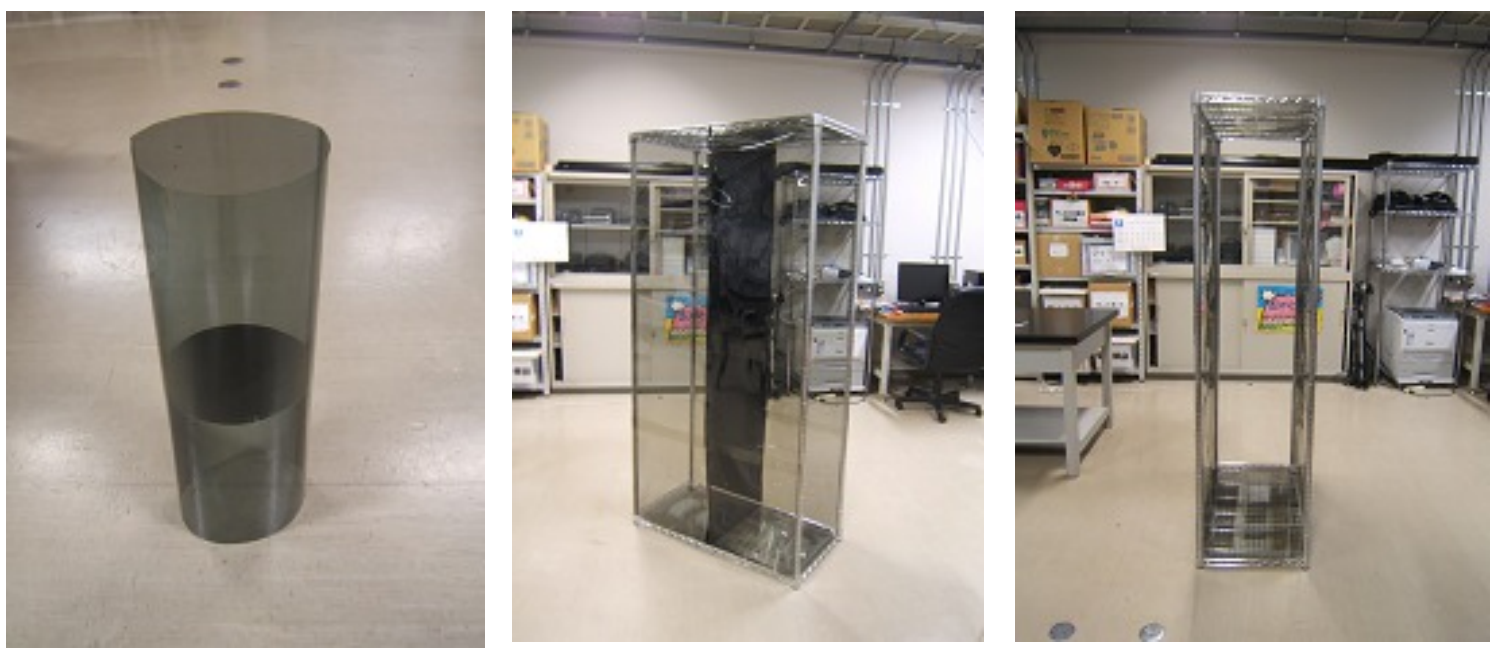

Figure 11. "Black wall" or "black plate" demonstration materials with polarization phenomena. 


\section{SUMMARY}

The activities of the out-of-curriculum student project team "Rika-Kobo" as well as several topics mainly related in the fields of optics and photonics to be offered in their various activities has been introduced. Although any statistical analysis data are available, their activities are believed to exhibit certain effects for the purpose of stimulating interests of children and students as well as their parents and other generations towards science and technology.

The respective activities performed by the student project team vary in wide ranges, as explained above, and have their own specific aims and targets, audience size, as well as locations. This fact means that in order to realize satisfactory and successful results in each of the activities, the student members are every time required to do enough preparation work and make certain adjustments in order to realize successful outcomes and appropriate clients' satisfactions. Accordingly, each of their activities provides the student members with effective and advantageous Project-BasedLearning (PBL) style experiences, which encourage the student members to achieve and improve their various skills and abilities necessary in their future career. Thus, those activities are also helpful for the student members to achieve and/or renew scientific knowledges, as well as various manufacturing experiences. Therefore, their activities can serve as an effective scheme for education and training of future engineers.

\section{ACKNOWLEDGEMENTS}

The authors are grateful to current and past student members of the student project team "Rika-Kobo" for their dedicated involvements in the activities.

\section{REFERENCES}

[1] Hasegawa, M., "New education scheme for college students through out-of-curriculum project activities," Intl. Journal of Modern Education Forum (IJMEF), Vol.4, Issue 3, pp.120-123 (2014).

[2] Hasegawa, M., "Case study on educational effects for university students of their out-of-curriculum project activities," Proc. of 2015 2nd Intl. Conf. on Educational Reform and Modern Management (ERMM2015), no.ERMM2015-E040, pp.205-208 (2015).

[3] Hasegawa, M., "Engineering educational effects for undergraduate students through out-of-curriculum project activities," Proc. of Intl. Conf. on Electrical Engineering (ICEE2016), no.90064 (2016).

[4] Hasegawa, M., "Roles and effects of activities of a student project team in engineering education for university students in lower grades," Proc. of 2013 IEEE Intl. Conf. on Teaching, Assessment, and Learning for Engineering (TALE2013), no.140, pp.87-90 (2013).

[5] Hasegawa, M. and Tokumitsu, S., "Spectra analysis in sunset color demonstrations with a white-color LED as a light source," to be included in Proc. of 18th Intl. Conf. on Physics Education (ICPE2016), (2016).

[6] Hasegawa, M., "A simplified experiment set for demonstrating optical communication with LEDs as light transmitting and receiving components," Proc. of 2013 Intl. Conf. on Physics Education (ICPE-EPEC2013), no.093.P1, pp.1151-1157 (2013).

[7] Hasegawa, M., "Use of LEDs as a light receiving component and their application to demonstration experiments for educational purposes," Proc. of 2015 IEEE Intl. Conf. on Teaching, Assessment, and Learning for Engineering (TALE2015), no.113, pp.31-35 (2015).

[8] Hasegawa, M., "Application of optical communication demonstration set employing LEDs both as light transmitting and receiving elements for education in various generations," Trans. Mat. Res. Soc. Japan (Transactions of the Materials Research Society of Japan), Vol.41, No.1, pp.17-20 (2016)

[9] Ogihara, J. and Hasegawa, M., "Simplified wavelength multiplied optical communication demonstration set with a white-color LED," Japanese Journal of Applied Physics Education, Vol.40, No.1, pp.59-62 (in Japanese) (2016). 